\title{
DISCOVERY OF A JUVENILE MASS MORTALITY BED OF FRESHWATER VIVIPARID GASTROPODS IN DECCAN INTERTRAPPEAN HORIZON OF BARGA, MADHYA PRADESH, INDIA
}

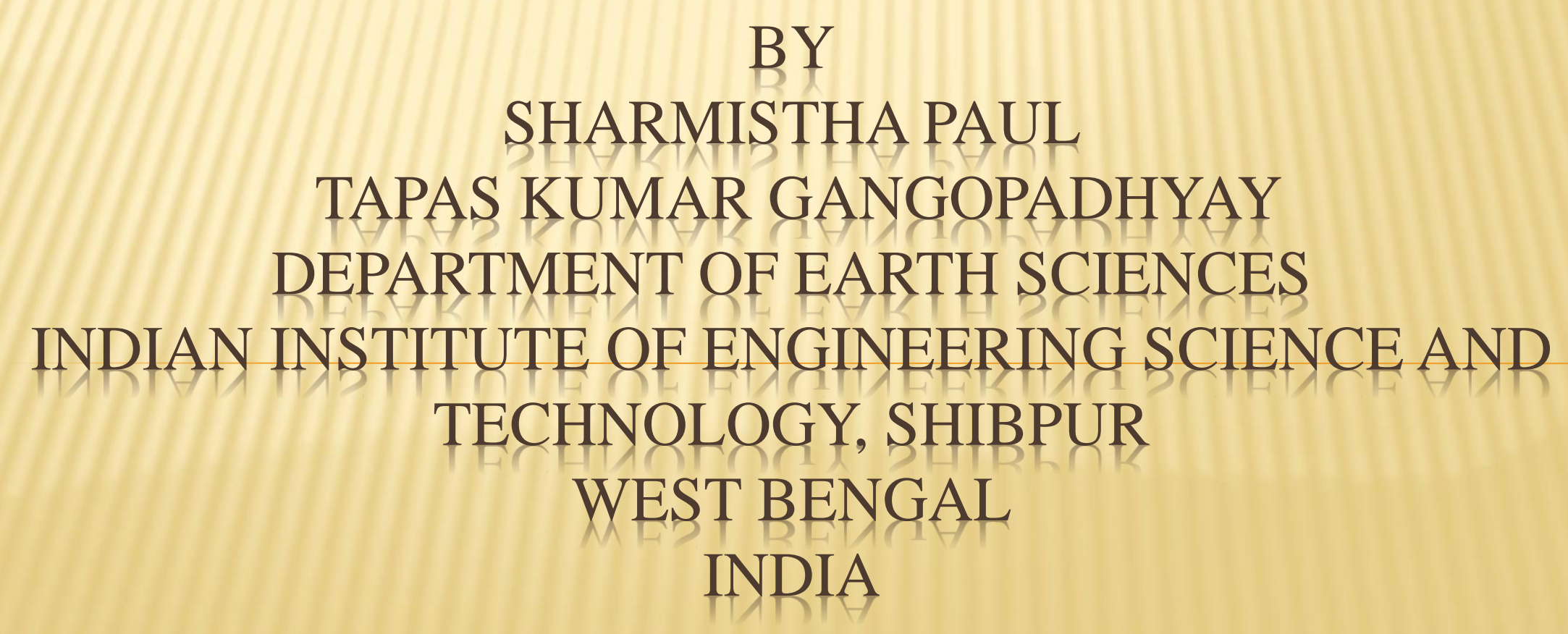




\section{DECCAN TRAPS OF INDIA}

$x$ It is solidified basaltic lava covering some 5lakh sq.kms essentially in Western, Central and part of South-eastern part of Indian Peninsula.

$x$ It is one of the largest igneous provinces of the world.

* Lava eruptions occurred around Cretaceous-Tertiary boundary in three phases: Phase-I, Phase-II and Phase-III, of which Phase-II is the most voluminous and severest.

During these eruptions there was sudden rise in temperature as well as emanations of toxic gasses like $\mathrm{CO}_{2}$ and $\mathrm{SO}_{2}$ etc. 
MAP SHOWING LOCATION OF DECCAN TRAP INDIA

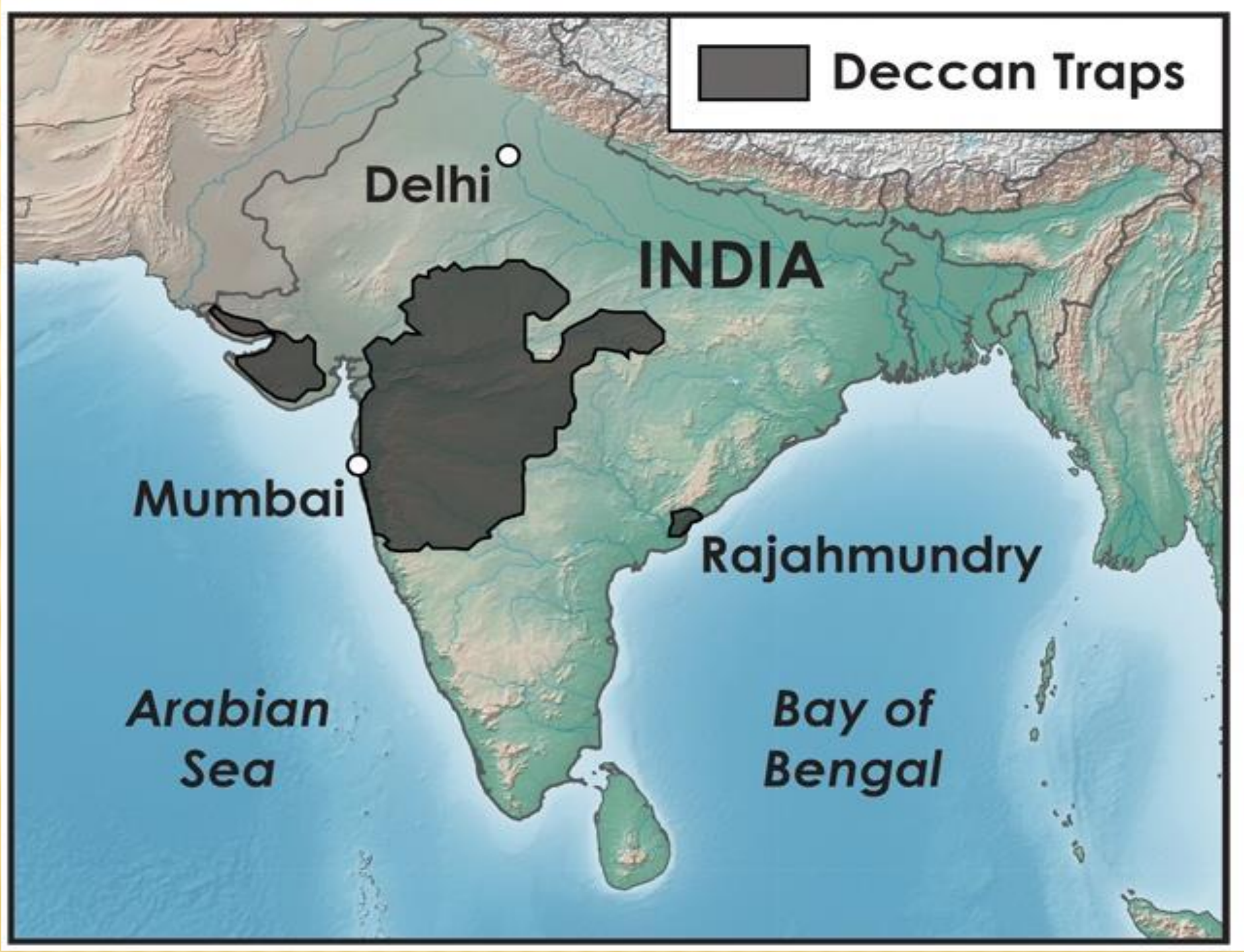




\section{DECCAN INTERTRAPPEAN HORIZON}

* It means sedimentary horizons (varying in thickness from few centimeters to several meters), fossiliferous or unfossiliferous occurring in between two basaltic eruptions. Maximum published age gap between two eruptive episodes is $2 \mathrm{Ma}$.

* These intertrappean horizons have been worked out for characterization of biotic evidences present like varied groups of vertebrate and invertebrate-both micro- and macro-organisms.

* The present case study is from one of such locations in Central India, namely Barga (Latitude: $23^{\circ} 13.574^{\prime} \mathrm{N}$; Longitude: $80^{\circ} 34.903^{\prime} \mathrm{E}$ ), some $100 \mathrm{~km}$ ESE of Jabalpur.

$x$ There we encountered a juvenile Viviparid gastropod mass mortality bed completely devoid of mature Viviparids. 


\section{LOCATION OF STUDY AREA}
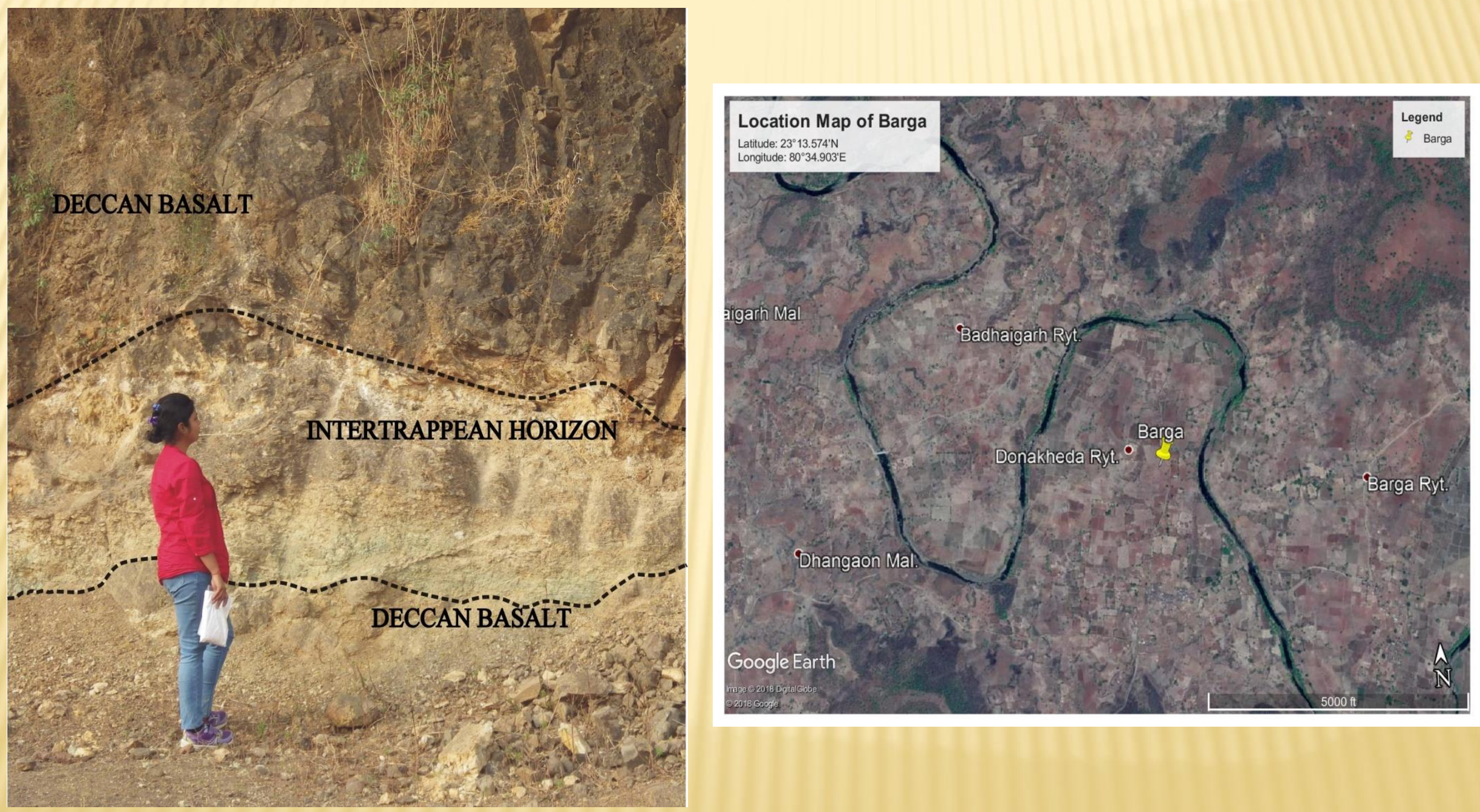


\section{RELEVANCE OF THE PRESENT STUDY}

* Actually intertrappean fossil study was initiated by Sowerby (1840) and first published by Hislop (1860). But it only describes the names of the molluscan fossil present and nothing more than that.

* Hartman (2008; pp. 1229) expressed that Hislop's species or genus level identification have been used in Indian publications of dissertations and this type of work has not expanded untill recently beyond geographic or stratigraphic occurrence.

Besides, he also expressed, "Continental molluscan paleontologists are rare even in the USA where the fossils are relatively plentiful in many states and geological periods".

* Our study takes into account recent researches on Viviparid gastropods and this type of venture is allowed by the world scientific community because in page.130 of the Treatise of Invertebrate Palaeontology, Part: ' $N$ ' it is stated "The ecology of living mollusca has better documented than for the most phyla of invertebrates and this information is directly applicable to the interpretation of Palaeoecology". 


\section{GEOGRAPHIC RISTRIBUTION OF XIVIPARIDS}

$\times$ The present distribution of Viviparid range covers all continents except South America (marked as black) where they are found as fossils

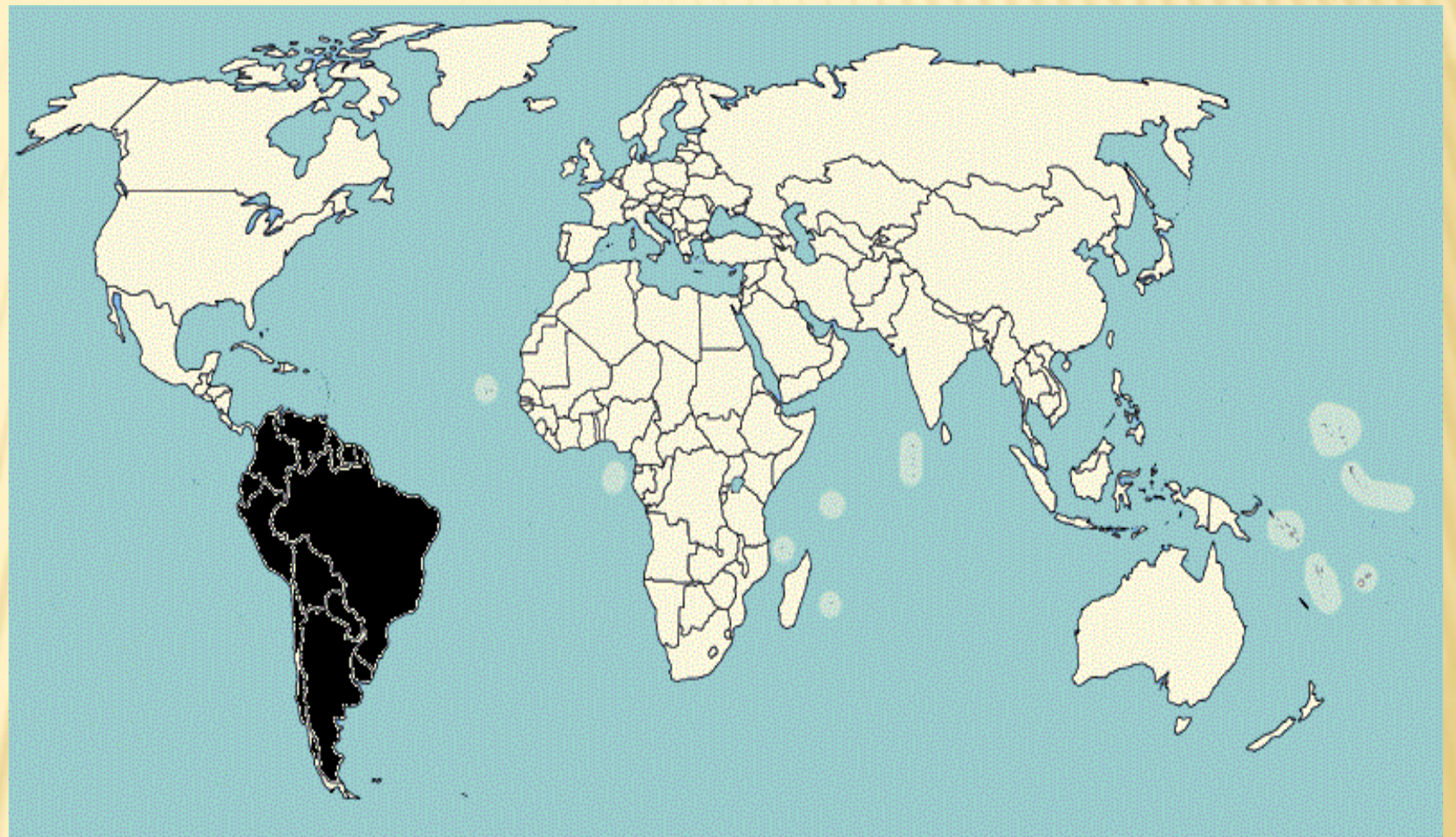




\section{TAXONOMY OF VIVIPARIDS}

Kingdom: Animalia Phylum: Mollusca Class: Gastropoda Subclass: Prosobranchia Family: Viviparidae Genus: Viviparus

Species: Viviparus normalis 


\section{XIVIPARID HABITAT}

* Viviparids live in large rivers, ox-bows and less frequently in lakes and heavily overgrown ponds. They prefer low-energy conditions where there is some vegetation and a muddy substrate (Clench and Fuller, 1965).

* Viviparus prefers habitats of medium values of factors like water transparency, temperature, $\mathrm{pH}$, calcium, phosphorus and organic matter.

* It prefers sandy, loamy, muddy or stony bottom. It is practically absent from seasonal water bodies and can be found partially bedded in the mud or silt of lakes, ponds or slower portions of streams (Pace, 1973).

* The characteristic pattern of occurrence of Viviparids makes their populations large enough to dominate the benthic fauna of rivers and lakes. In our case, it is solely visible.

$\times$ The dominance of youngest individuals $(90 \%)$ was noted in shallow place to depth of $\mathbf{2 m}$. In the deeper part they comprise $50 \%$ of all Viviparus. 


\section{REPRODUCTION OF GASTROPODS WITH SPECIAL EMPHASIS ON VIVIPARIDS}

* Most terrestrial and marine gastropods are iteroparous.

Most freshwater snails particularly pulmonates are semelparous.

The native freshwater Caenogastropods are mainly oviparous except for Viviparus and Potamopyrgus.

* Freshwater viviparids are iteroparous and ovoviviparous. Intensity of their reproduction varies with season. Reproduction is most intensive in late spring.

* Viviparid embryos develop within the egg capsules (Fretter and Graham, 1978). In the mother's brood chamber the embryos are arranged according to the advancement of their development.

Viviparid juveniles are released into the water as mobile miniature forms of adult (See next figure). 


\section{RECENT VIVIPARID JUVENILES}

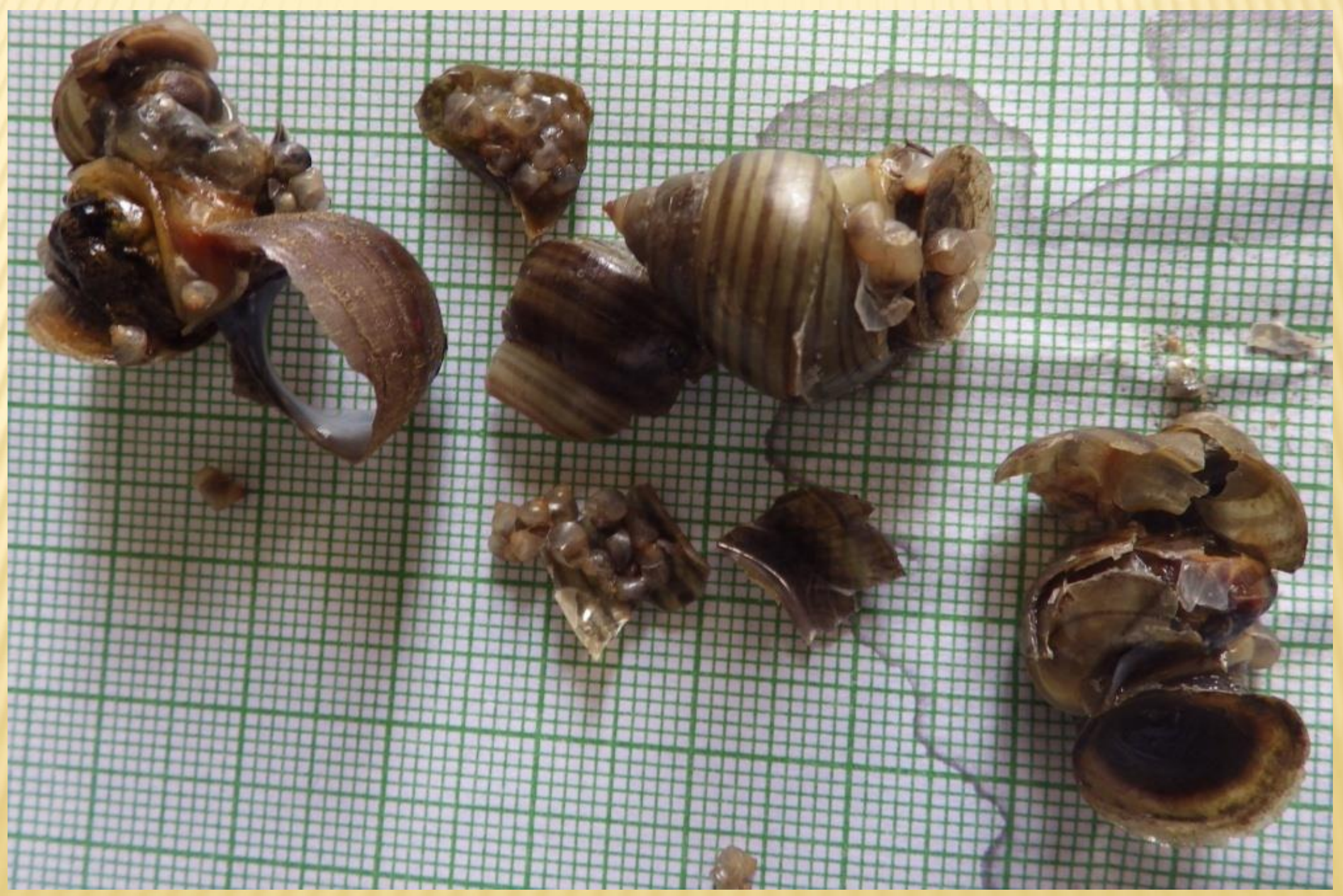




\section{FOSSIL УIYIPARID JUYENILES OF PRESENT STUDY AREA}

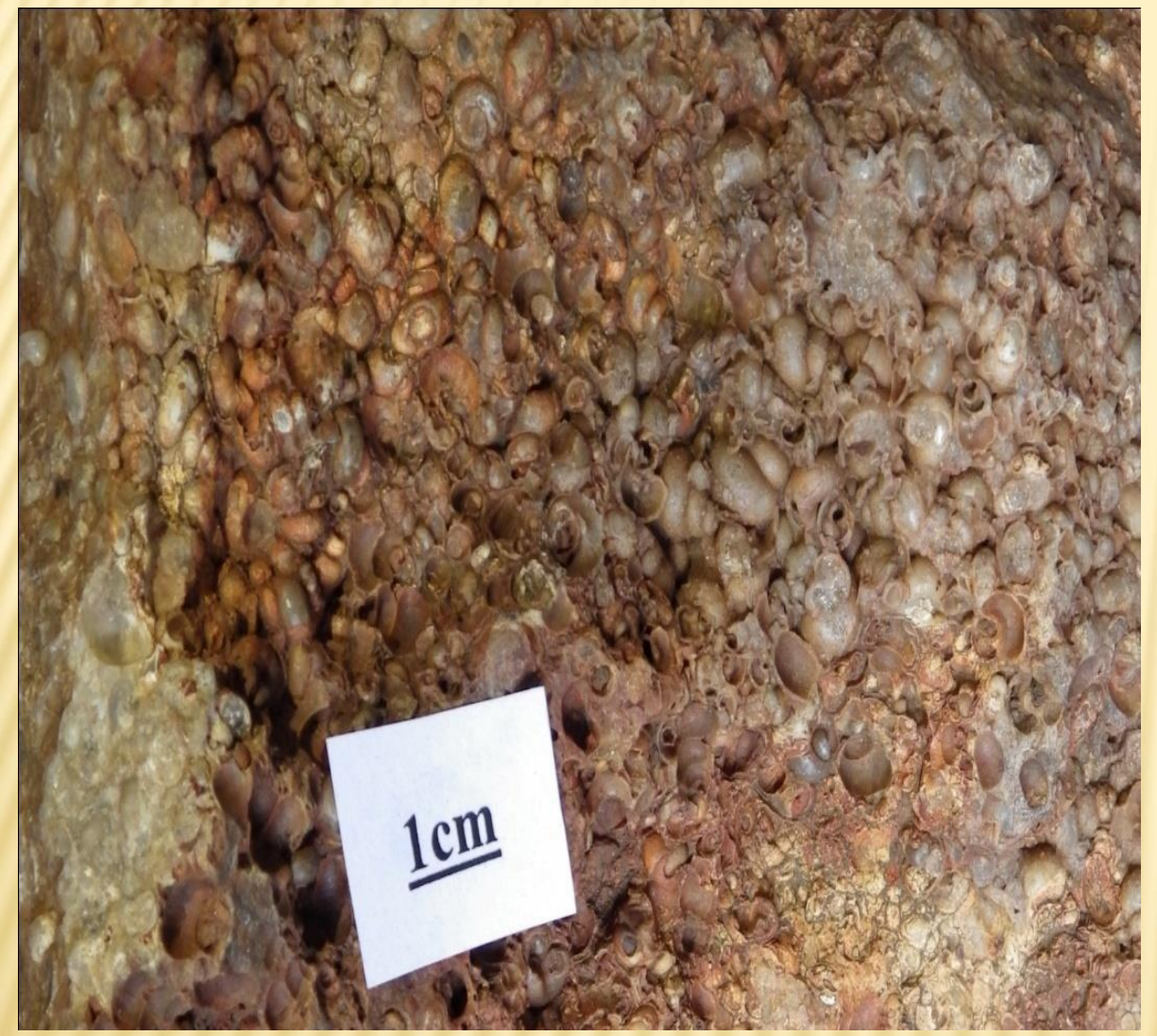

* Note varied orientation of the unimodal fossil juveniles which debarred preparation of sizefrequency diagram and the population. The nature of the assemblage indicates it a census type population of Hallam (1972). 


\section{CHARACTERISATION OF VIVIPARIDS}

Stanczykowska (1960) made four size classes of Viviparids:

* Class I $\rightarrow$ Shells of height and width: 5.0-8.0mm (our juvenile fossil shells belong to this class).

Class II $\rightarrow$ Shells of height and width: $8.1-12.0 \mathrm{~mm}$.

* Class III $\rightarrow$ Shells of height and widht: 12.1-20.0mm

- Class IV $\rightarrow$ height $>25 \mathrm{~mm}$ and width $>20 \mathrm{~mm}$.

* The proportion of youngest class is small in general. It seems that very small percentage of the youngest snail is a result of their rapid growth which makes them move to next size class already in the first month of their life. This explanation was experimentally confirmed by Jakubik and Lewandowski, 2007. 


\section{VIVIPARUS LIFESTYLE}

* Viviparidae display two life history traits:

A) constant and independent of the habitat type

B)Varying under the effect of different ecological conditions.

* The maximum shell density may reach $2700 / \mathrm{m}^{2}$ in the zone of occurrence of young individuals. The water body is comparable to the oxbow lakes. The autumn decrease in the viviparid density in all the aggregations was largely associated with autumn migration of larger shells deep into the water. 


\section{MASS MORTALITY AND FEW RECENT REPORTS}

* Mass mortality event (MME) is a single disastrous event which wipes out large population of a single species within a short period of time. This phenomenon has occurred in the geologic past, several times in several areas, yet reports of mass mortality events are getting wide circulation from 1940 onwards.

\section{$\times$ Recent reports of $\mathrm{MME}$}

1) 1,50,000 antelopes in Kazakhstan died within a span of few weeks, suggested cause is blood poisoning due to a latent bacterium inside the antelopes bodies

2)On a single day, in 2014 in Queensland, Australia over 45,000 flying foxes(Fruit Bats) died due to intense heat. 


\section{FACTORS RESPONSIBLE FOR MME}

* The severest factor from all documented examples is disease and it accounts for $26.3 \%$ of all cases while biotoxicity is responsible for $15.6 \%$.

* Considering 727 published MMEs affecting 2,407 animal populations, PNAS, USA (2015) published nine accepted causes for mass mortality. They are:

- Disease

- Biotoxicity

- Desiccation

- Multiple stressors

- Oxygen depletion

- Starvation

- Thermal stress

- Toxicity and

\section{Weather.}

Other less important factors are stress associated with reproduction, high temperature, overcrowding, opportunistic invaders, pathogens and possibly inbreeding. This report further emphasized that disease and multiple stressor are the sole causes. 


\section{FEW REPORTED CASES OF MME FROM GEOLOGIC PAST}

* Mass mortality of a dominant invasive species, Corbicula fluminea in response to an extreme climatic event; W. G. McDowell et.al: During an extreme summer of 2012,over $99 \%$ of Corbula died in about a 100 sq.km study area of Broad river,Georgia.Besides thermal stress, total dissolved phosphorus (TDP) and soluble reactive phosphorus (SRP) were also higher in those areas.

* Mass mortality caused by toxic dinoflagellate blooms in a Berriassian-Valanginian Lagoon, Bornholm, Denmark; NoeNygaard et.al 1987: Monospecific Neomiodon Bivalve and Viviparus gastropod were affected by massmortality. Although Neomiodon bivalves probably died due to biotoxicity of Dinoflagellate blooms and Viviparid gastropod by desiccation.

Studies on mass summer mortalities of cultured Zhikong scallops in China; Jie Xiao et.al. 2005 : In this case, high summer temperature, gill cavity infection, Prokaryotic inclusion in soft tissue, stress associated with reproduction, overcrowding, interbreeding were suggested to be the main causes for this mortality of the scallops. continued 


\section{FEW REPORTED CASES OF MМE FROM GEOLOGIC PAST}

* Huge amount of 'Fish kills' especially juveniles in localized areas are very common. General factor is reduced oxygen level which, in turn, may be due to factors like drought, algal bloom, overpopulation or a sustained increase in water temperature. However, juvenile mass mortality may be due to severe cold also (From Wikipedia).

* Mass mortality of fishes in the Santana Formation(Lower Cretaceous) of northeast Brazil; Martill etal.2008: Millimeter thick fish bone bed might have been formed due to reduced level of salinity or surfacewater, oxygen, release of $\mathrm{H}_{2} \mathrm{~S}$ from sediments, or by toxic dinoflagellate or cyanobacterial blooms. 


\section{CONCLUDING DISCUSSION}

Our study area shows presence of fossil juvenile Viviparids (5-8mm), Class: I of Stanczykowska (1960) in a niche where viviparids constitute about $90 \%$ of the gastropod fossils. Presence of palm fossil wood fragments indicate that vegetation was there at that time. The entire horizon is overlain and underlain by Deccan Basalts indicating that the horizon faced severe temperature rise as well as toxic gas $\left(\mathrm{CO}_{2} \mathrm{SO}_{2}\right.$ and others) emanations. Thus environmental toxicity and sudden temperature rise were the major cause for this instantaneous catastrophic death of the mollusca as a whole.

It is experimentally proved that Class: I Viviparids remains only one month in that size at a shallow depth of $2 \mathrm{~m}$. Presence of clusters of Class: I fossil Viviparids indicate that MME here occurred within one month of their birth. Probably this has happened in autumn and it is testified by absolute absence of larger Viviparid snails which might have gone to deeper part to combat ensuing winter. The locality shows nearer ox-bow lake condition of meandering river. Besides, excellent mould preservation indicate least transport. The nature of the assemblage indicates no taphonomic loss. The unimodal size distribution further suggests that the assemblage represents one generation only which was killed almost instantaneously. It is thus considered census type population in the sense of Hallam, 1972. Sudden rise in temperature and abiological toxic effect of gaseous emanations from the eruptive fissures made the environment thermally and toxically inhospitable causing enmasse death of juvenile Viviparid gastropods in the form of MME. 


\section{ACKNOWLEDGEMENT}

Dr. Arif Sikder of Virginia Commonwealth University helped a lot to be here for presentation.

Institute authority of IIEST Shibpur, West Bengal, INDIA for permitting us to do the work and present the research findings in this platform.

Forest authorities of Government of Madhya Pradesh, INDIA also helped in various ways in the fieldwork. 


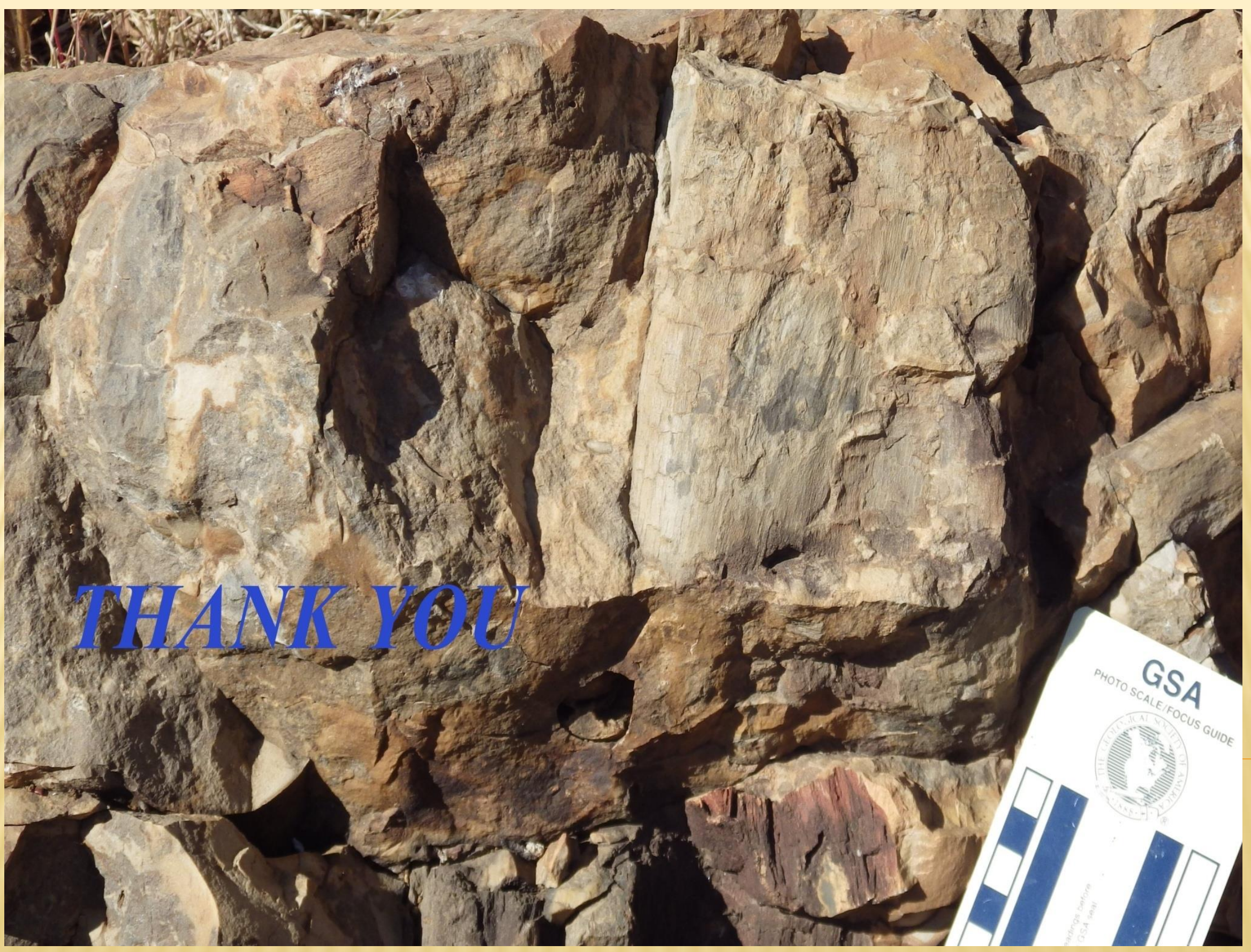

